Research Article

\title{
Experimental and Numerical Investigation of Pressure Fluctuation in a Low-Specific-Speed Centrifugal Pump with a Gap Drainage Impeller
}

\author{
Li Zhang, ${ }^{1}$ Hui Li, ${ }^{1}$ Hong Xu, ${ }^{2}$ Weidong Shi, ${ }^{3}$ Yang Yang, Wanhong Wang, \\ and Ling Zhou $\mathbb{D}^{1,4}$ \\ ${ }^{1}$ National Research Center of Pumps, Jiangsu University, Zhenjiang 212013, China \\ ${ }^{2}$ National Research Center of Emergency Equipment, PLA Army Logistics University, Chongqing 401331, China \\ ${ }^{3}$ School of Mechanical Engineering, Nantong University, Nantong 226019, China \\ ${ }^{4}$ Jiangsu Shentong Valve Co., Ltd., Nantong 226232, China
}

Correspondence should be addressed to Ling Zhou; lingzhou@ujs.edu.cn

Received 20 January 2021; Accepted 21 June 2021; Published 1 July 2021

Academic Editor: Desmond Adair

Copyright (c) $2021 \mathrm{Li}$ Zhang et al. This is an open access article distributed under the Creative Commons Attribution License, which permits unrestricted use, distribution, and reproduction in any medium, provided the original work is properly cited.

In order to analyze the effect of impeller with different slot widths on the performance of the low-specific-speed centrifugal pumps, based on the impeller of a single-stage pump with the specific speed of 21 , two gap drainage schemes with slot widths of $1.5 \mathrm{~mm}$ and $6.0 \mathrm{~mm}$, slot diameter of $180 \mathrm{~mm}$, and lap length of $5 \mathrm{~mm}$ were designed. Both experimental and numerical simulation methods were applied to compare the steady performance, which includes the head, efficiency, and the internal flow field distribution, and the unsteady pressure pulsation performance between new designed pumps and the original pump. The results show that gap drainage would cause a certain degree of head reduction, but a smaller slot width could achieve higher efficiency. Meanwhile, a reasonable open seam scheme can reduce the development of pressure pulsation, which provides experience and reference for the stable operation of low-specific-speed centrifugal pumps.

\section{Introduction}

Low-specific-speed centrifugal pumps are often used in low flow rate and high head occasions [1,2]. Compared with ordinary centrifugal pumps, its impeller was characterized with small flow coefficient, small blade outlet angle, large impeller outer diameter, and small exit width, which would cause narrow and long impeller flow channel and intensify the diffusion of liquid in the impeller [3-5]. Therefore, the complex flow structures, such as secondary flow and separated flow, occur [6-8], which not only directly affect the pump efficiency, but also have a great impact on the pressure pulsation performance [9-11].

In recent years, the stability of internal flow field in fans and compressors has been investigated [12-15], and it could be improved significantly by setting reasonable slot on the blades [16-18]. The operating mechanics of centrifugal pump impeller based on blade machinery have many similarities with fans and compressors, and the main difference is the physical property difference of working medium $[19,20]$. Therefore, lots of researchers have tried to apply this slot impeller in the centrifugal pump. Yuan et al. [21] employed the numerical simulation to analyze the inner flow field of a centrifugal pump impeller with splitter blade and obtained that the split has an effect on the stability of impeller outlet flow, the occurrence of the flow separation, and the structure of "jet-wake." Kergourlay et al. [22] applied the experimental and numerical ways to study the performance difference of centrifugal pump with splitter blades and without splitter blades. Compared to the pump without splitter blades, the periphery velocities and pressures of impeller with splitter blades are more homogeneous; meanwhile, the head and radial thrust increase, and the pressure fluctuations decrease. Georgiev and Vlaev [23] used the CFD methodology to compare the influence of different blade design on the flow field and 
presented that the slotted blade can preserve the pumping capacity with $40 \%$ lower power requirement than the conventional blades. Li et al. [24] successfully applied the gap drainage technology to a six-blade low-specific-speed centrifugal pump, and the results showed that the gap drainage could effectively improve the impeller performance, and they also found that the influence degree and area of the gap drainage on the performance of the centrifugal pump exhibit significant differences in different low-specific-speed centrifugal pumps. Zhu and Chen [25] utilized the numerical and experimental investigation to compare the difference of the cavitation performance between the conventional and gap impeller, and they obtained that the structure of gap impeller can effectively suppress the generation of cavitation especially in large flow area. Zhang et al. [26] adopted the numerical method to study the influence of a slot on the cavitation performance of the centrifugal pump and found that the slot can suppress the reverse flow and improve the cavitation performance at low flow rate, while causing a head decrease in the whole flow rate.

In this paper, a typical centrifugal pump with the specific speed of 21 was selected to study the effect of slot width on the performance and internal flow field of low-specific-speed centrifugal pump. The pressure pulsation at impeller outlet, volute tongue, and volute water cross position were monitored, and the time domain diagrams at these points were compared. This research provides reference for improving performance and stability of low-specific-speed centrifugal pump.

\section{Geometry and Numerical Methods}

2.1. Geometry and Parameters. In order to study the influence of slot width on the internal flow field and pressure pulsation performance of centrifugal pump, the ZA20-250 model pump was selected with flow rate $Q_{d}=10 \mathrm{~m}^{3} / \mathrm{h}$ (the subscript character " $d$ " represents design condition), head $H_{d}=80 \mathrm{~m}$, impeller blade number $z=3$, impeller outlet diameter $D_{2}=259 \mathrm{~mm}$, the rotational speed $n=2900 \mathrm{rpm}$, and specific speed $n_{s}=21$. Two new slot schemes are shown in Table 1, and the location of gap drainage is shown in Figure 1.

The three-dimensional modeling of whole flow fluid domain includes impeller water body, volute water body, pump case water body, and front and rear clearance of wearring water body. To ensure that the flow is fully developed, the length of the inlet water body and outlet water body is four times that of the impeller inlet diameter and volute outlet dimeter, respectively. Figure 2 shows the model of each calculation domain.

2.2. Grid Independence Analysis. By using structured grids on full flow field with the software ANSYS ICEM, five different meshing number schemes were established to eliminate the influence of number of grid points on the calculation results. The head and efficiency of centrifugal pump under the rated condition $\left(1.0 Q_{d}\right)$ working condition were used as a measurement of grid independence, and the calculation results are listed in Table 2.

Table 2 shows that the head and efficiency will be gradually stable when the number of grid increases. When the mesh quantity increases to 4.3 million, the fluctuation range of head is within $0.3 \mathrm{~m}$, and the maximum efficiency fluctuation is $0.19 \%$. It can be considered that when the number of meshes increases to 4.3 million, the calculation accuracy can meet the requirements. Therefore, considering the calculation accuracy and the demand of computing resources, the grid scheme of 4365848 elements is finally selected for the subsequent analysis in the original model (without slot).

In order to obtain a better solution of the flow in the slot, different grid layers were set in different slot widths. Considering the limitations of computer hardware, 25 layers were chosen for slot width of $1.5 \mathrm{~mm}$, and 90 layers were chosen for slot width of $6.0 \mathrm{~mm}$. The mesh in the boundary layer is decreased from the inside to the outside, and finally, the $y+$ of the blade surface for the two widths is $0.5<y+<3.8$ and $0.2<y+<3.5$, respectively. Figure 3 shows the diagrams of grid for each computational subdomain and the grid details of impeller with slot, impeller without slot, and volute tongue.

\subsection{Turbulence Model and Boundary Condition Setting.} The medium in the whole calculation domain is incompressible water, and the finite volume method was used to discrete the control equation in the calculation domain. The standard $k$-omega turbulence model and the SIMPLE algorithm, which is used for the coupling of pressure and velocity in the calculation, were selected for numerical calculation. The result of the steady state calculation was adopted as the initial value of the unsteady calculation to accelerate convergence. The time step was set as $0.00017241 \mathrm{~s}$, which is equivalent to impeller rotation time of 3 degrees. The total calculation time is $0.16551724 \mathrm{~s}$, which matches 8 rotation cycles. To ensure the accuracy of the calculation, the convergence accuracy of the solver was set as 0.0001 ; when the residuals drop to less than $10^{-4}$, the calculation converges, and then, calculation terminates. The setting of boundary conditions is as follows:

(1) The inlet boundary condition is set as pressure inlet, and the value is $1 \mathrm{~atm}$.

(2) The solid wall is set as nonslip wall with $0.025 \mathrm{~mm}$ wall roughness.

(3) The calculation domain of impeller is rotational, and the rest are static. The frozen rotor model was applied for the dynamic-static interface.

(4) Mass flow outlet is used to control the different flow conditions.

\section{Experimental Validation}

3.1. Testing Apparatus. The test apparatus was set up according to the design requirements of the centrifugal pump test. The system mainly includes a three-phase 
TABLE 1: The parameters of two slot schemes.

\begin{tabular}{lccc}
\hline Case & Slot diameter $D(\mathrm{~mm})$ & Blade overlap length $L(\mathrm{~mm})$ & Slot width $E(\mathrm{~mm})$ \\
\hline Model 1 & 180 & 5 & 1.5 \\
Model 2 & 180 & 5 & 6.0 \\
\hline
\end{tabular}

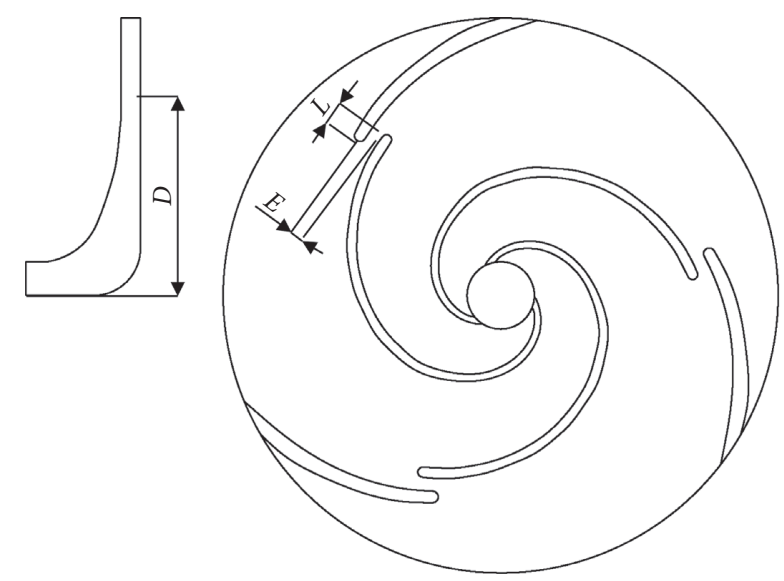

Figure 1: Parameters of gap drainage on impeller blades.

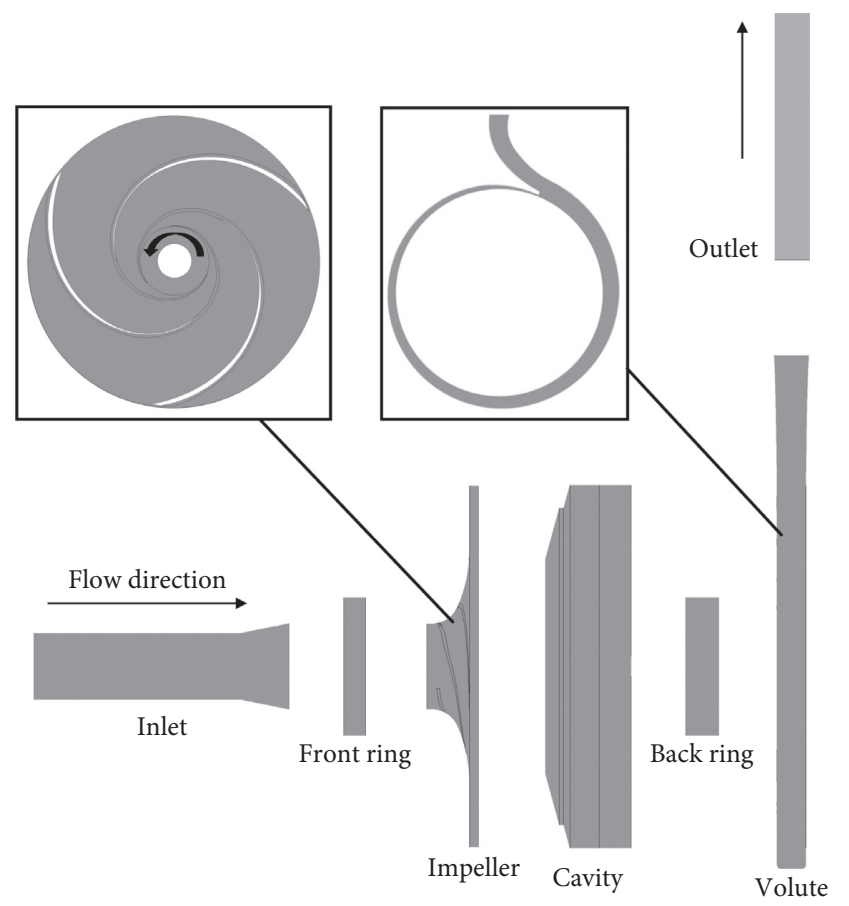

Figure 2: Assembly diagram of the fluid domain.

TABLE 2: Grid independence analysis.

\begin{tabular}{lcc}
\hline Number of grid elements & Head $(\mathrm{m})$ & Efficiency $(\%)$ \\
\hline 2169713 & 83.51 & 25.57 \\
3251493 & 83.34 & 25.98 \\
4365848 & 82.53 & 26.73 \\
5246214 & 82.49 & 26.92 \\
5941363 & 82.51 & 26.74 \\
\hline
\end{tabular}

asynchronous motor, a DN20 electromagnetic flowmeter, gate valves on inlet and outlet pipelines, pressure gauge on inlet and outlet pipelines, a centrifugal pump, and a closed water tank. The start and stop of the equipment are controlled by the electrical control unit, and the acquisition and storage of the test data are completed by the computer. The CY200 digital pressure sensor that uses the single chip microcomputer system (SOC) chip to process and store pressure signal is applied to measure the pressure fluctuation in real time. The range of the measurement is $0 \sim 2 \mathrm{MPa}$, the accuracy is $\pm 0.1 \% \mathrm{FS}$, and the maximum sampling frequency is $1000 \mathrm{~Hz}$. The $485-20$ signal collector is used to receive the pressure pulsation signals of multiple pressure sensors at the same time under different flow conditions and transmit them to computer acquisition software for data storage and further processing. Considering the asymmetry of the volute structure, the monitoring points $\mathrm{W} 1 \sim \mathrm{W} 6$ along the circumferential direction, Y1 at impeller outlet, G1 at volute tongue, and $\mathrm{O} 1$ at pump outlet, were arranged to detect the pressure pulsation in the flow field, where the W1, W3, W4, and W5 were uniformly arranged at $90^{\circ}$. For the restrictions of pump structure and sensor size, pressure sensors were only installed at $\mathrm{W} 2, \mathrm{~W} 3, \mathrm{~W} 5, \mathrm{~W} 6$, and $\mathrm{O} 1$, and the pressure pulsation at the other points, where the pressure sensor was unable to be installed, was obtained by the numerical calculation method. The physical drawing of the test device is shown in Figure 4.

3.2. Comparison of Experimental Results and Numerical Results. The numerical calculation and experimental results of the original model pump (without slot) performance were compared in Figure 5. It can be found that the numerical simulation of performance agrees well with the test result. The head error obtained from the two methods was within $2.5 \%$, and the efficiency error was within $1 \%$ under the $1.0 Q_{d}$ working condition. The maximum errors of head and efficiency appear at $1.4 Q_{d}$, and the maximum errors are $4.7 \%$ and $3.1 \%$, respectively. In general, the performance prediction results of numerical simulation are in good agreement with the experimental results.

The pressure coefficient $C_{p}$, which is defined in function 1 , is introduced as an indicator to measure the pressure pulsation intensity.

$$
C_{p}=\frac{p-\bar{p}}{0.5 \rho u^{2}}
$$

where $p$ is the pressure of a certain time at monitoring point, $\mathrm{Pa} ; \bar{p}$ is the average pressure in a period at monitoring points, $\mathrm{Pa} ; \rho$ represents the density of medium, $\mathrm{kg} / \mathrm{m}^{3}$; and $u$ is the circumferential velocity of impeller outlet, $\mathrm{m} / \mathrm{s}$. 


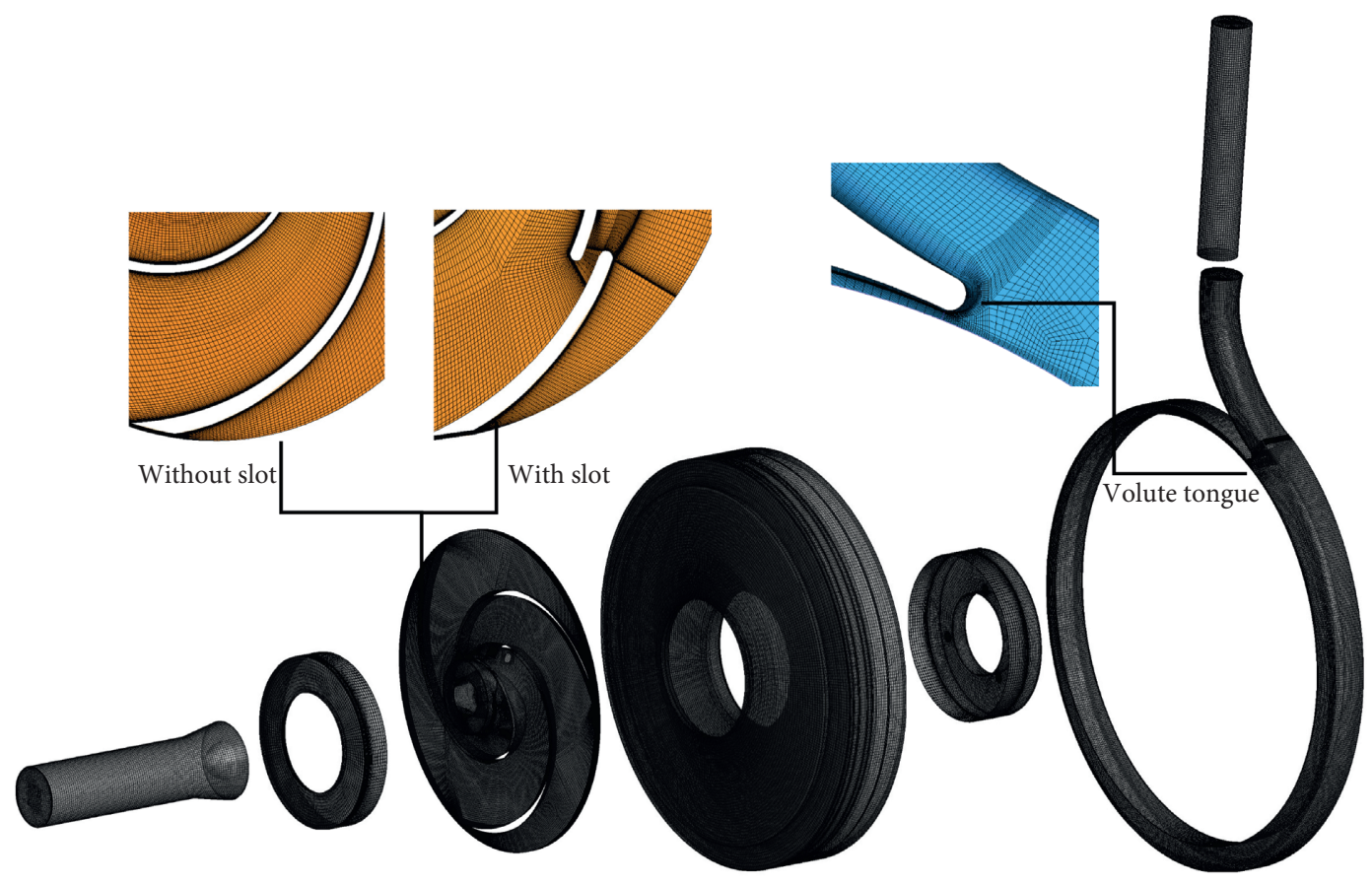

Figure 3: Calculated domain and grid details.

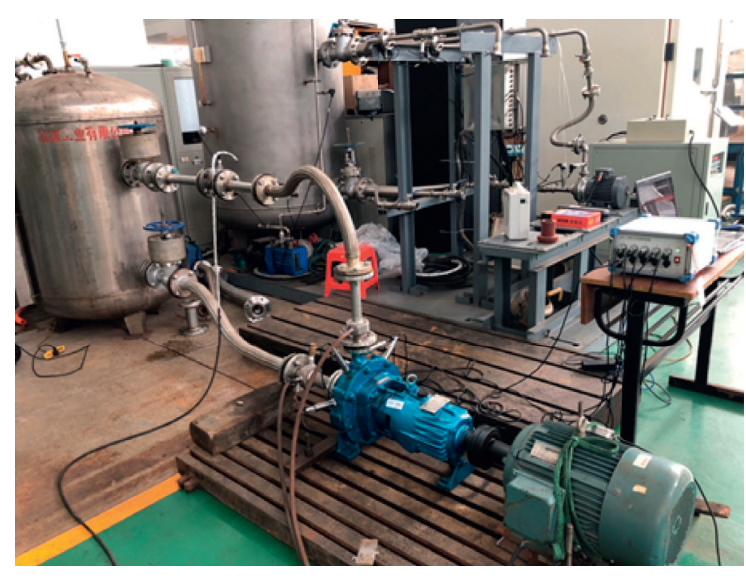

(a)

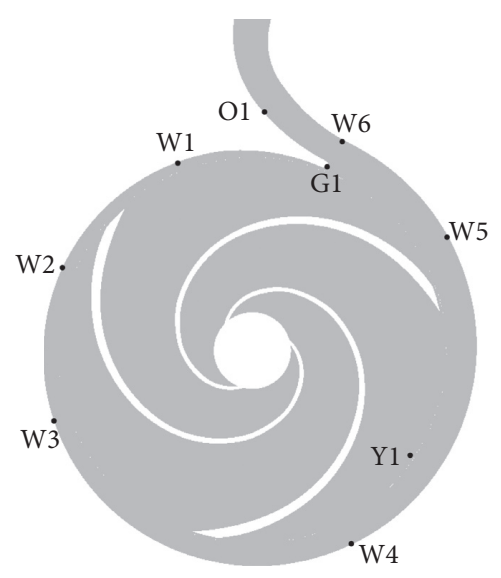

(b)

Figure 4: Test equipment and arrangement of pressure pulsation monitoring points.

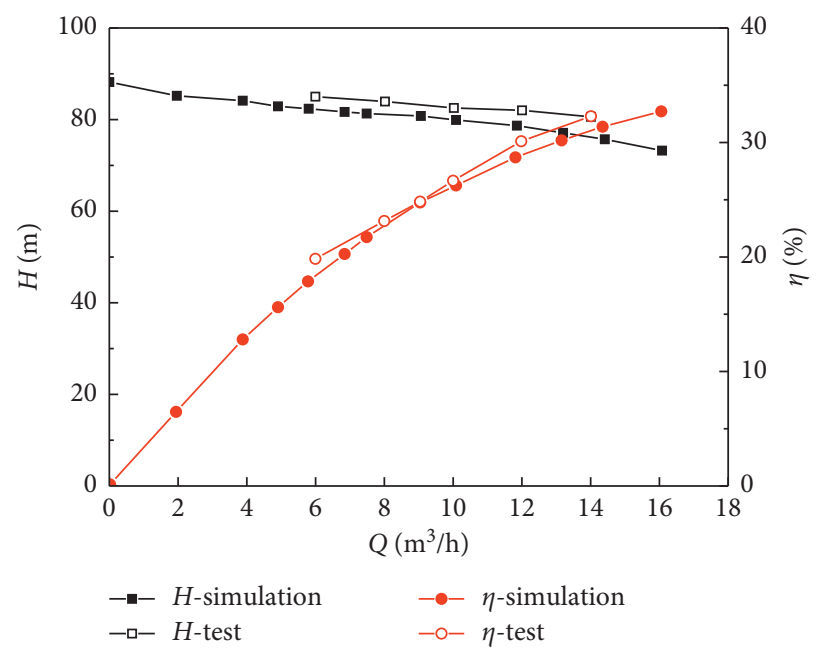

FIGURE 5: Comparison between simulation results and test results. 
Figure 6 shows the comparison of the original model pump pressure fluctuation between the experimental results and the numerical results at the monitoring points $\mathrm{O} 1, \mathrm{~W} 6$, $\mathrm{W} 5, \mathrm{~W} 3$, and W2 under $1.0 Q_{d}$ working condition. From the time domain distribution performance of the pressure pulsation, it can be seen that the numbers of peaks and troughs from the numerical and the experimental results are the same with the blade number in a cycle. The amplitude of pressure pulsation from the test result is basically the same as that from the numerical calculation results at the monitoring points $\mathrm{O} 1$ and $\mathrm{W} 6$; at monitor points $\mathrm{W} 2, \mathrm{~W} 3$, and $\mathrm{W} 5$, the amplitude of test results and numerical calculation results fluctuated; furthermore, the local variation of pressure pulsation was not captured at some moments. The reason for this phenomenon is mainly due to the limited conditions that include the low sampling frequency and large sampling interval of the used pressure sensor; therefore, it failed to capture the variation of pressure fluctuation during sampling interval. There are also some differences between the test results and the numerical simulation results, and it may be mainly because the flow field in the test is much more complex than that in the simulation. Compared with the flow field of numerical simulation, the actual flow field in the test is inevitably affected by some factors, such as the swing of the shaft system, the vibration of the unit, the coupling of the flow components, and the influence of the electromagnetic systems of the motor. These factors will affect the results of pressure pulsation. But, in general, the numerical results are coincident with the experimental results. In conclusion, the numerical calculation method used in this paper is relatively accurate in predicting the pump performance and pressure pulsation characteristic of the selected low-specific-speed centrifugal pump model. The numerical calculation method can be used to analyze the influence of gap drainage impeller on the transient characteristics of low specific speed centrifugal pump.

\section{Results and Analysis}

4.1. Effect of Slot Width on the Pump Performance. Table 3 shows the pump performance of original model, model 1 , and model 2 at $0.6 Q_{d}, 1.0 Q_{d}$, and $1.4 Q_{d}$, respectively. Table 3 shows the head of the three model, at flow rates $0.6 Q_{d}, 1.0 Q_{d}$, and $1.4 Q_{d}$, and the head is arranged from high to low as follows: the original model, model 1 , model 2 , and the head of model 2 is about $5 \mathrm{~m}$ lower than that of the original model under each working condition. The order of efficiency from high to low is model 2 , model 1 , the original model, and the maximum efficiency improvement rate is $3.9 \%$. When the slot diameter is $180 \mathrm{~mm}$, the head of centrifugal pump decreases, and the downward trend intensifies with the increasement of slot width, and the efficiency of gap drainage impeller is higher than that of the original model.

It can also be found that the optimal operating point of the centrifugal pump does not appear at $1.0 Q_{d}$. Because there is no specific design method for low-specific-speed centrifugal pump, the traditional design method of centrifugal pump is still used. According to the design method of centrifugal pump, the larger the flow rate, the higher the efficiency, the larger the specific speed, and the higher the efficiency. Therefore, the centrifugal pump with low-specific-speed is designed based on the maximum flow design method, and the core component of this method is to amplify the given design flow and specific speed, so the efficiency curve of the amplified pump would cover that of the original required one within a certain flow range, and the efficiency at the rated flow condition has also been improved. This results in the fact that the flow rate at the optimal operating point is often greater than that at the rated operating point.

\subsection{The Influence of Slot Width on the Flow Field Distribution.} In order to explore the performance differences between the slot impeller and the traditional impeller with different parameters, the internal flow fields of each model were analyzed and compared. The flow inside the impeller is asymmetric because of the influence of the volute. To facilitate the subsequent analysis, the flow channel near the tongue position was marked as channel 1 , and the flow channels in counterclockwise direction were marked as channels 2 and 3 .

Figure 7 shows the velocity and streamline distribution of the original model, model 1 , and model 2 at different flow conditions. For $0.6 Q_{d}$, a significant flow separation and vortex at the blade pressure surface and the impeller outlet of channel 1 occur in the original model. The strength of flow separation at blade pressure surface in model 1 is slightly higher than that in the original model, and the vortex at impeller outlet of channel 1 decreases significantly. The extrusion effects of the offset blade cause the flow separation, and the accumulation of the tail liquid intensifies the development of the flow separation, but meanwhile, the gap has a certain flow capacity, which reduces the liquid blockage at the impeller outlet and weakens the vortex of impeller outlet. The vortex at the trailing edge of impeller blade in model 2 disappears with the increasement of the slot width; this is because the enhancement of flow capacity further reduces the blockage of the liquid at the impeller outlet, and then the vortex disappears. Meanwhile, the flow direction of the liquid changes when it flows through the gap. The mainstream in the near wall region no longer flows completely along the tangential direction of the blade, and there is a downward angle at the gap, which enhances the mainstream suppression on the flow separation of blade pressure side and represses the development of the flow separation [27].

For $1.0 Q_{d}$, the liquid flow direction of model 1 and model 2 at the impeller outlet of channel 1 is obviously different from that of the original model. In the original model, the liquid flow direction at the trailing edge of the blade is not tangential to the blade but points to the volute, indicating that the liquid diffuses too fast in the channel and is more to separate; the offset blade increases the constraint ability to the liquid in the near-wall region of the offset blade, and then the liquid flows tangentially along the blade. However, due to the extrusion of the offset blade in model 1, it is also found that the flow separation on the pressure 

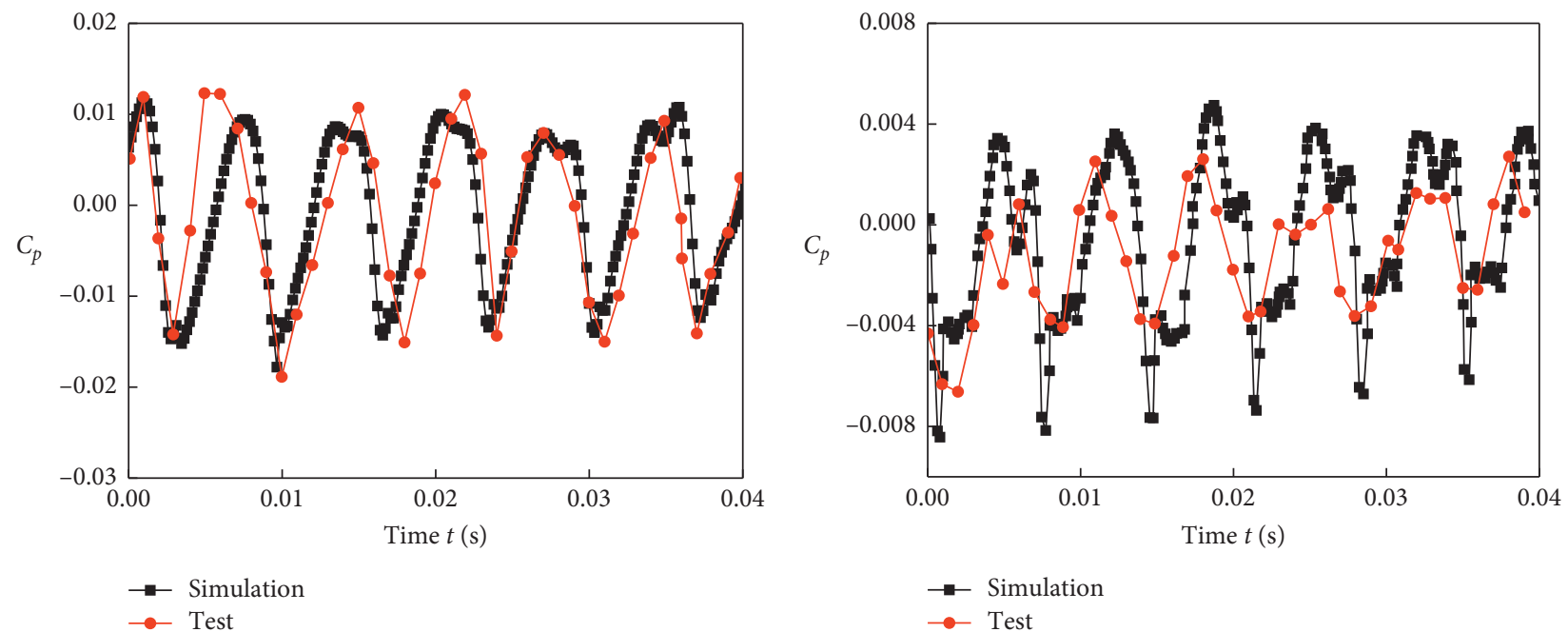

(a)

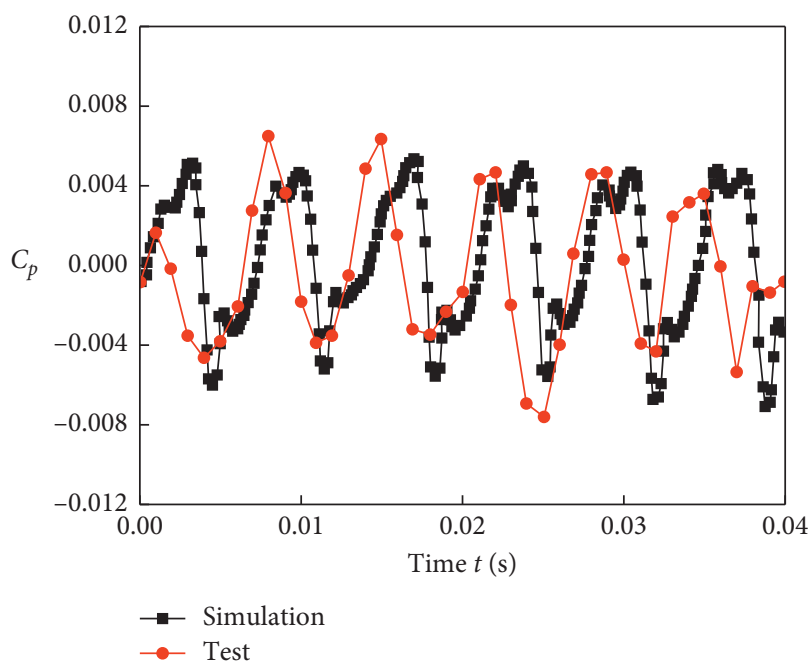

(b)

(c)

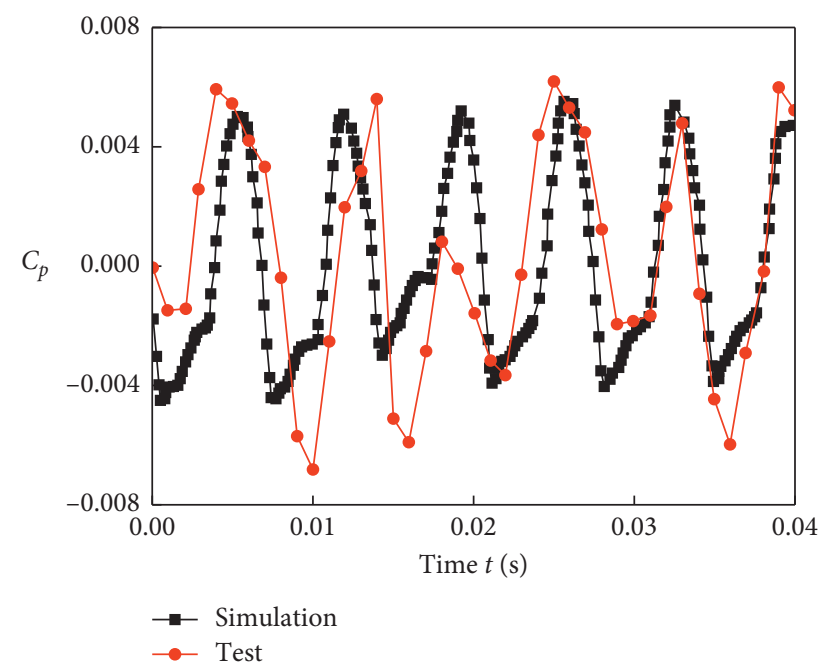

(d)

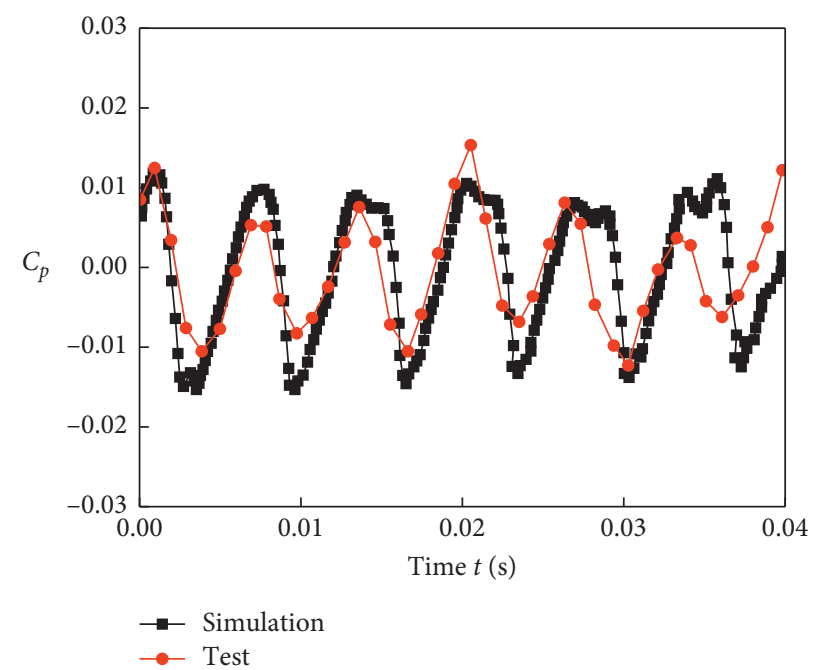

(e)

FIGURE 6: Comparison of pressure pulsation test results and CFD results at 1.0Qd. (a) O1. (b) W2. (c) W3. (d) W5. (e) W6. 
TABLE 3: Comparison of hydraulic performance of different schemes.

\begin{tabular}{lccc}
\hline Flow rate & Schemes & Head $H(\mathrm{~m})$ & Efficiency $\eta(\%)$ \\
\hline \multirow{3}{*}{$0.6 Q_{d}$} & Original model & 84.7 & 19.8 \\
& Model 1 & 81.51 & 19.91 \\
\hline \multirow{3}{*}{$1.0 Q_{d}$} & Model 2 & 79.14 & 20.26 \\
& Original model & 82.5 & 26.7 \\
& Model 1 & 79.16 & 26.98 \\
$1.4 Q_{d}$ & Model 2 & 76.86 & 27.1 \\
& Original model & 80.6 & 32.3 \\
& Model 1 & 76.88 & 33.51 \\
\hline
\end{tabular}

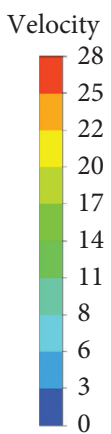

$\left(\mathrm{m} \cdot \mathrm{s}^{-1}\right)$

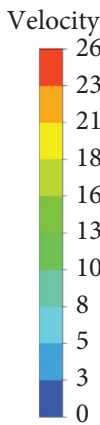

$\left(\mathrm{m} \cdot \mathrm{s}^{-1}\right)$

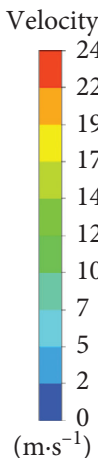

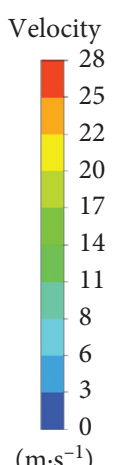

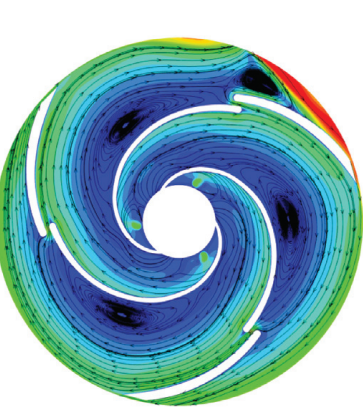

(a)

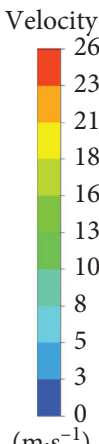

$\left(\mathrm{m} \cdot \mathrm{s}^{-1}\right)$
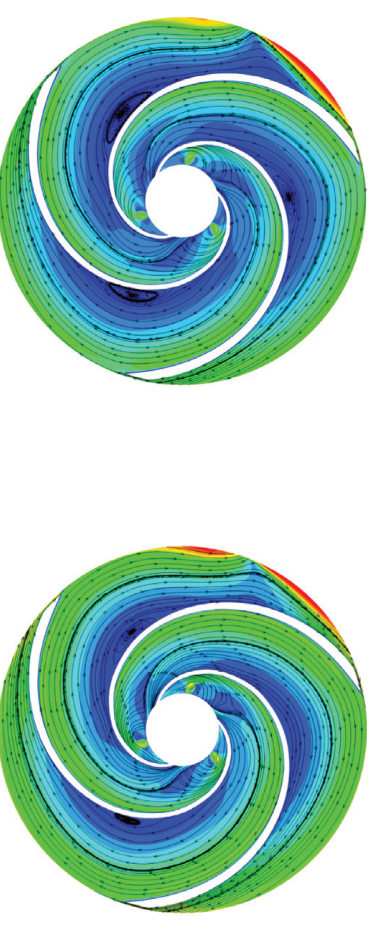

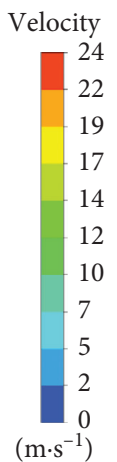

(b)

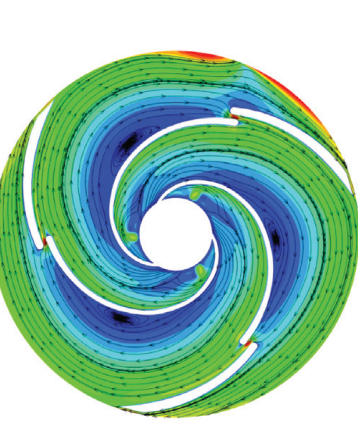

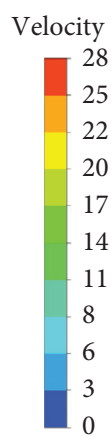

$\left(\mathrm{m} \cdot \mathrm{s}^{-1}\right)$
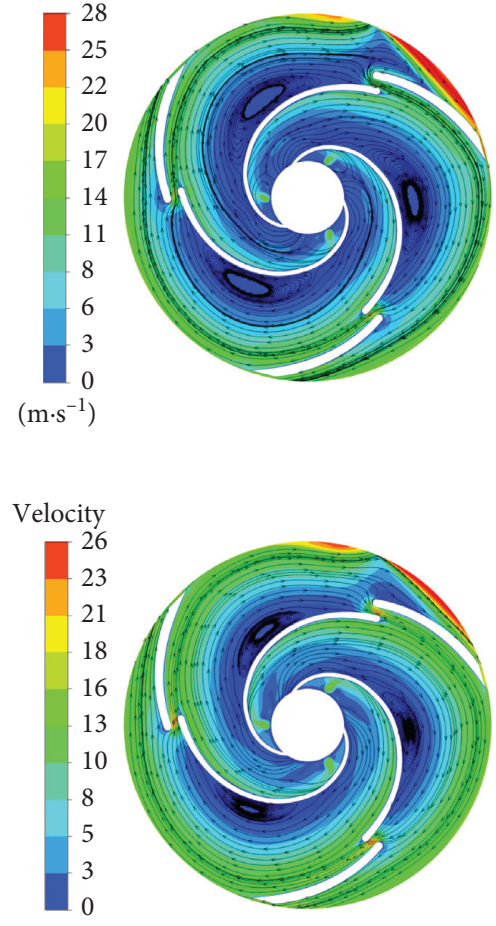

$\left(\mathrm{m} \cdot \mathrm{s}^{-1}\right)$
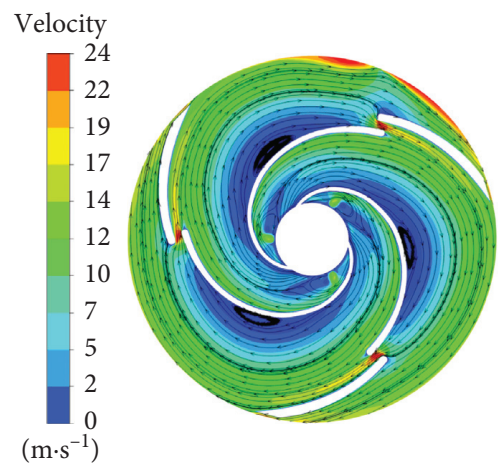

(c)

Figure 7: Streamline distribution on middle section of impeller (from left to right: original model, model 1, model 2). (a) $0.6 Q_{d \cdot}$. (b) $1.0 Q_{d}$. (c) $1.4 Q_{d}$. 
surface of the blade is enhanced compared with the original model. With the increasement of slot width in model 2, the area of low-speed zone in channel 1 of impeller outlet gradually decreases, then the flow at impeller outlet improves, and the flow separation on blade pressure surface weakens. This indicates that the gap at the trailing edge of the blade can improve the flow condition of impeller outlet; however, the flow separation can cause the accumulation of fluid at the tail due to the extrusion of the offset blade, which intensifies the flow separation at the pressure surface of the blade, to a certain extent [28]. This phenomenon is improved with the increase of gap width.

For $1.4 Q_{d}$, the internal flow of the impeller passage is more regular than that of $0.6 Q_{d}$ and $1.0 Q_{d}$. Although flow separation on the pressure surface of the blade still exists, its strength declines significantly when compared with the low flow rate. The flow separation intensity of flow channel in model 1 is higher than that in the original model. The suppression of mainstream on flow separation is enhanced with the increase of flow rate; therefore, the flow exhibits much more stable than that at low flow rate. The flow capacity at the gap of model 2 enhances when slot width increases, weakening the blocking phenomenon and improving liquid outflow. Meanwhile, a lot of the mainstream flows into adjacent channels through the gap and generates jet flow, which increases the flow velocity near the gap. The big velocity difference between jet and mainstream leads to the impact and improves energy loss produced during the liquid mixing.

Figure 8 shows the pressure distribution on the middle section of the impeller in the original model, model 1 , and model 2 under different flow rates. It can be found that the pressure distribution of model 1 resembles that of the original model, but the high-pressure area in channel 1 of impeller outlet decreases. The impeller outlet pressure is reduced with the increase of slot width, and the low-pressure zone of channel 1 at impeller outlet develops towards volute. With the increase of the slot width, the pressure of the impeller outlet in model 2 further decreases, because the increase of the slot width leads to a lot of high-pressure liquid flow into the adjacent channel through the gap, weakening the influence on performance of impeller. The high-pressure liquid passes through the gap to the suction surface and is mixed with the low-pressure liquid, which aggravates the energy loss of the liquid. The impeller outlet pressure of model 2 is significantly lower than that of the original model and model 1, and this indicates that the impeller boost capacity will be greatly reduced if a large gap is set at the trailing edge of the blade.

\subsection{Effects of Slot Width on Pressure Pulsation Characteristics.} Figure 9 shows the time-domain characteristics of pressure fluctuation for the original model, model 1, and model 2 at impeller monitoring points $\mathrm{Y} 1$ under $0.6 Q_{d}, 1.0 Q_{d}$ and $1.4 Q_{d}$, respectively. It illustrates that trough amplitude of model 1 and model 2 is larger than that of the original model, and strong waveform distortion occurs at the peak positions of model 1 under $0.6 Q_{d}$; the pressure pulsation amplitude of model 2 is larger than that of the original model under $1.0 Q_{d}$ and $1.4 Q_{d}$, and the pressure pulsation amplitude further rises with the increase of slot width.

Figure 10 shows the time domain characteristics of pressure fluctuation for the original model, model 1 , and model 2 at volute monitoring points $\mathrm{W} 1, \mathrm{~W} 3, \mathrm{~W} 4$, and W5 under $0.6 Q_{d}, 1.0 Q_{d}$ and $1.4 Q_{d}$ respectively. At $0.6 Q_{d}$, as shown in Figures 10(a) 10(d), a strong waveform distortion occurs at W1 near the tongue and gradually disappears when it propagates downstream along the volute channel. The pressure fluctuation waveforms of model 1 and original model are similar at W1, and there is no significant difference in amplitude, while the pressure fluctuation amplitude of model 2 increases significantly compared with the original model. The waveform distortion of the original model, model 1, and 2 decreases rapidly at W3, except a small and local waveform distortion that occurs at the trough. At W4 and W5, the pressure pulsation waveform distortion of model 1 and model 2 is improved, but the pulsation amplitude is slightly higher than that of the original model.

At $1.0 Q_{d}$, as shown in Figures 10(e) 10(h), the waveform distortion in the pressure pulsation of model 1 decreases gradually during the propagation from $\mathrm{W} 1$ to $\mathrm{W} 5$ and then progressively evolves into a stable periodic change. Finally, the amplitude of pressure fluctuation decreases significantly at W5. In model 2, the pulse signal generates more intense decrease of waveform distortion than that in model 1 during the process of propagation to the downstream channel; meanwhile, the pulse amplitude oscillation turns up at trough of W4, but the amplitude decreases significantly. At $1.4 Q_{d}$, as shown in Figures 10(i) 10(l), there is no significant difference in the pressure pulsation between model 2 and the original model at $\mathrm{W} 1$ and $\mathrm{W} 3$; the pressure fluctuation amplitude of model 2 is higher than that of the original model, but the pressure fluctuation shows severe attenuation in the propagation to downstream channel, and the pressure fluctuation amplitude at W5 is far lower than that of the original model. In conclusion, when the slot diameter is $180 \mathrm{~mm}$, the pressure fluctuation amplitude increases in the upstream of the volute channel and decreases rapidly during the propagation to the downstream channel. The pressure fluctuation amplitude in the downstream of the volute channel is far lower than that of the original model, and with the increase of the slot width, the decrease of the fluctuation amplitude is more obvious.

Figure 11 shows the time domain characteristics of pressure fluctuation for the original model, model 1 , and model 2 at tongue monitoring points $\mathrm{G} 1$ under $0.6 Q_{d}, 1.0 Q_{d}$ and $1.4 Q_{d}$, respectively. It illustrates that the intensity of pressure fluctuation at the tongue is significantly stronger than that inside the impeller and volute, and the pressure fluctuation amplitude is reduced with the increase of flow rate. At $0.6 Q_{d}$, the pulsation amplitude of model 1 decreases compared to the original model, but there is a certain waveform distortion; the pulse amplitude of model 2 is close to that of the original model; in addition, waveform distortion disappears. At $1.0 Q_{d}$, the pulse amplitude of model 1 and model 2 is bigger than that of the original model, but the 

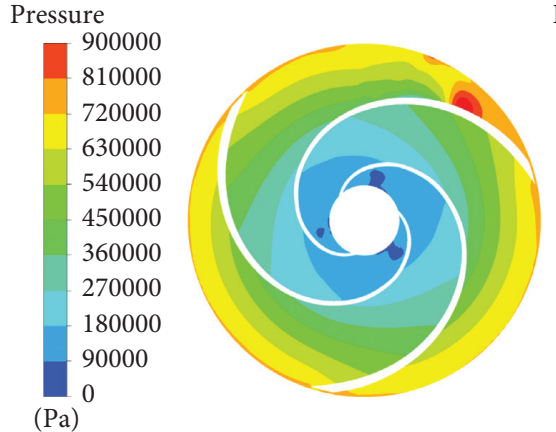

(Pa)

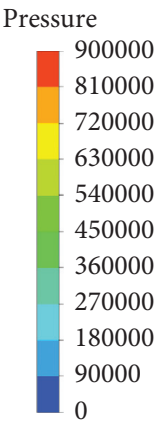

(Pa)

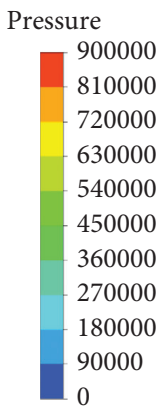

(Pa)

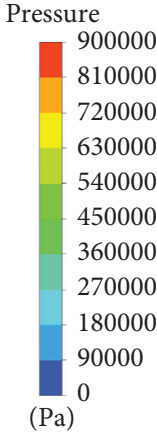

Pressure

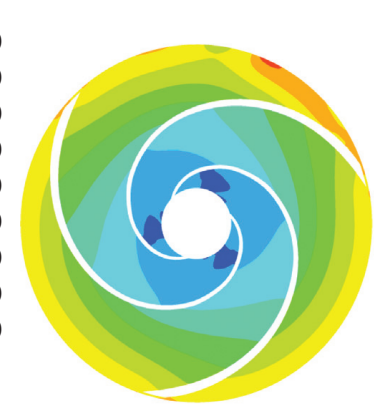

)

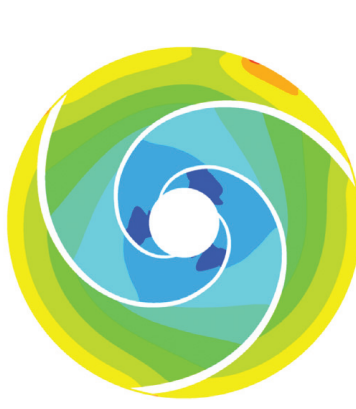

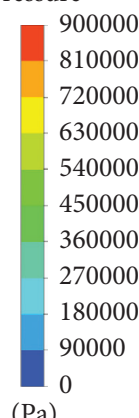

(Pa)

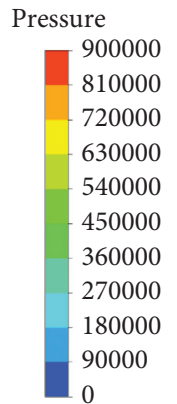

(Pa)

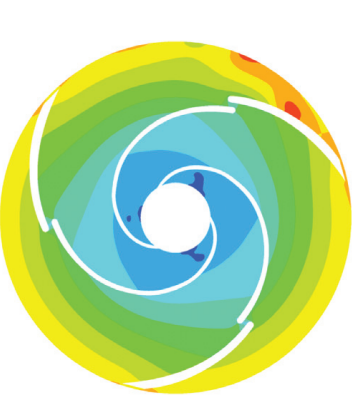

(a)



(b)

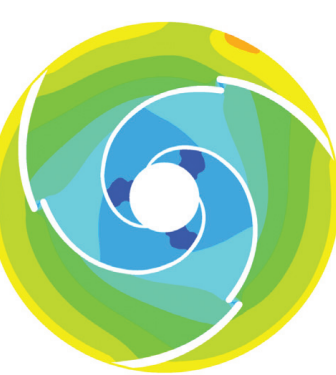

(c)
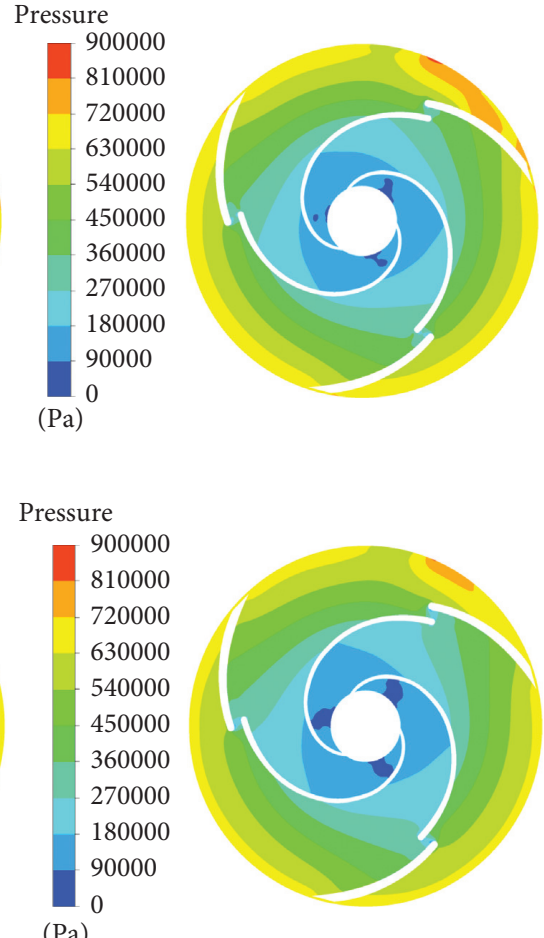

(Pa)

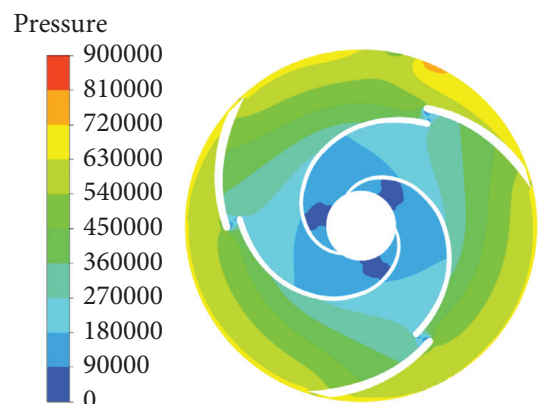

(Pa)

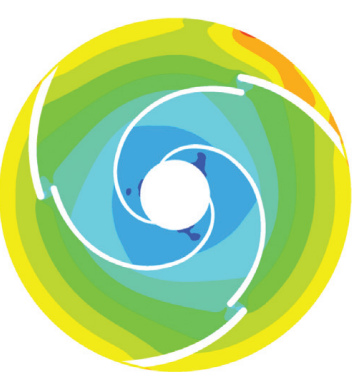

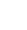




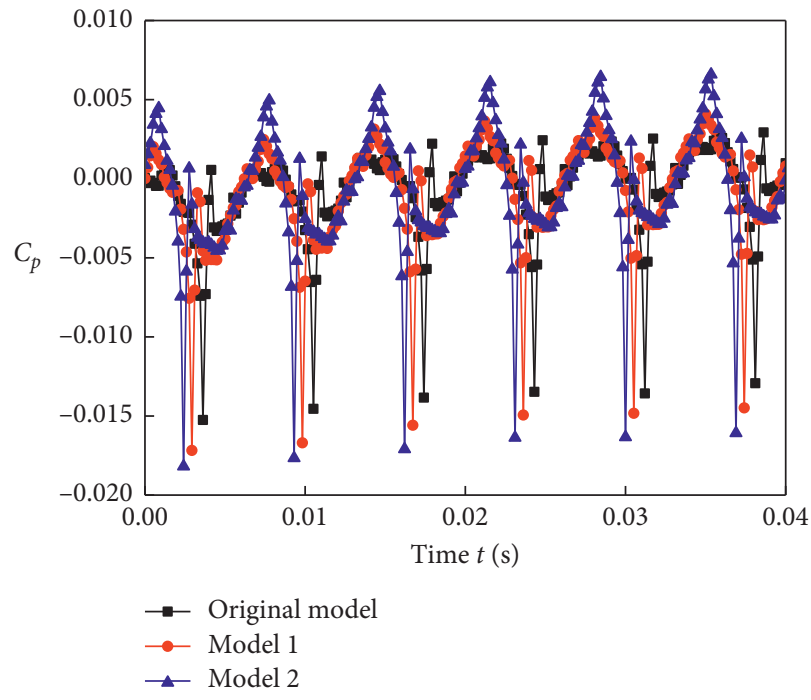

(c)

FIGURE 9: Time distribution of pressure pulsation at the impeller outlet. (a) $0.6 Q_{d}$. (b) $1.0 Q_{d}$. (c) $1.4 Q_{d}$.

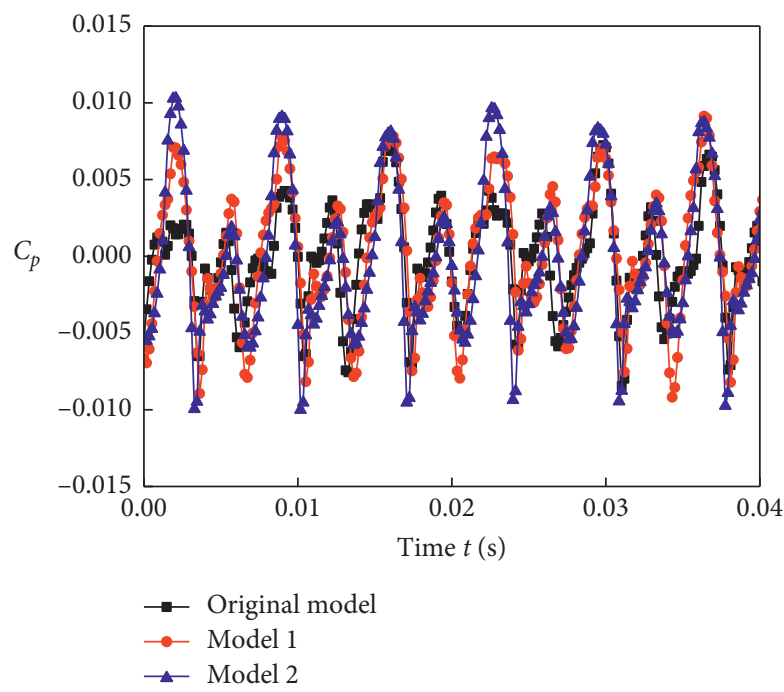

(a)

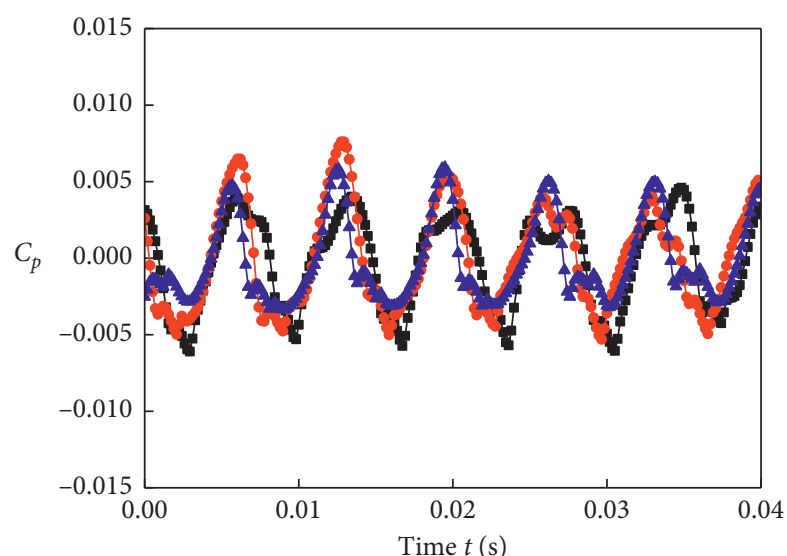

$\rightarrow-$ Original model

- Model 1

$\rightarrow$ Model 2

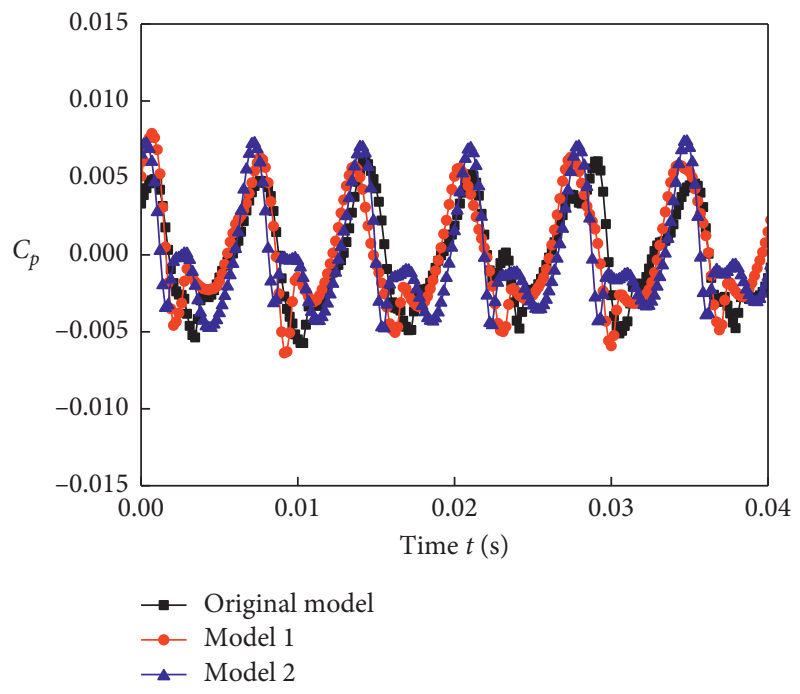

(b)

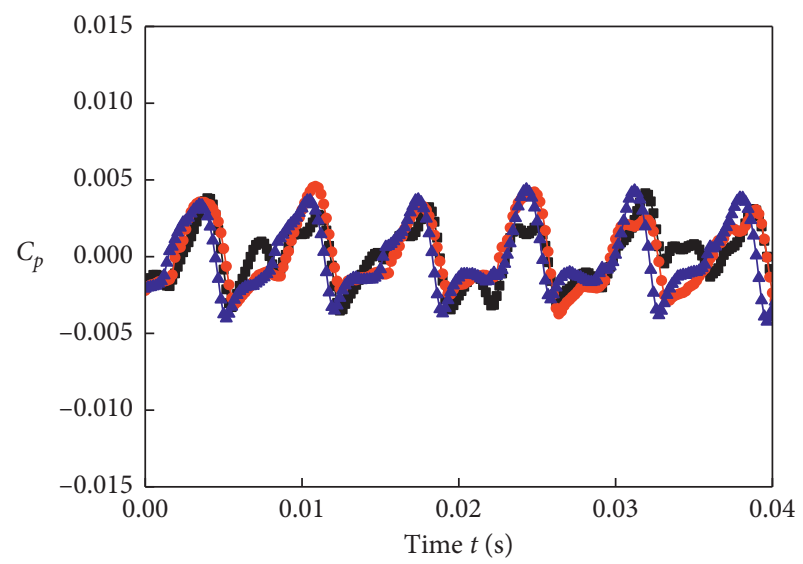

- Original model

$\rightarrow$ Model 1

$\rightarrow$ Model 2

(c) 


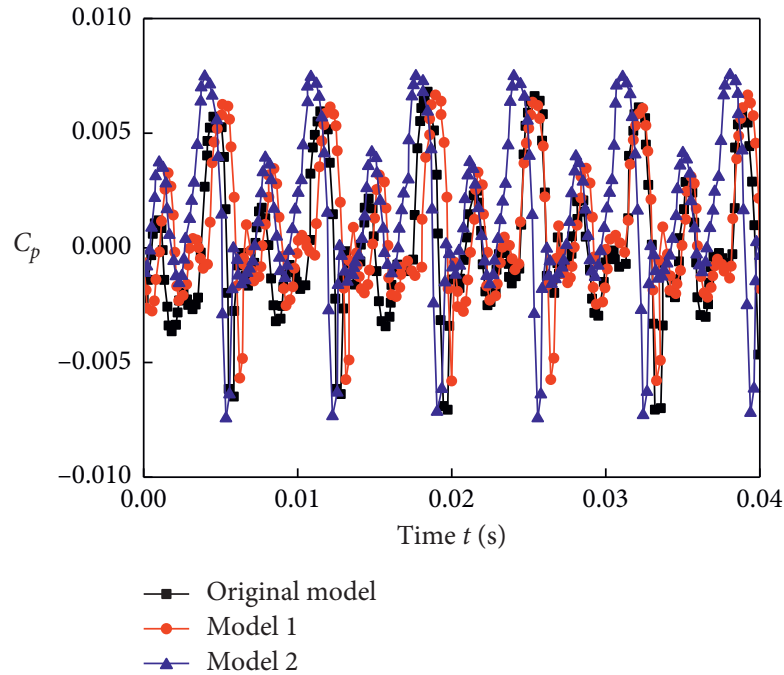

(e)

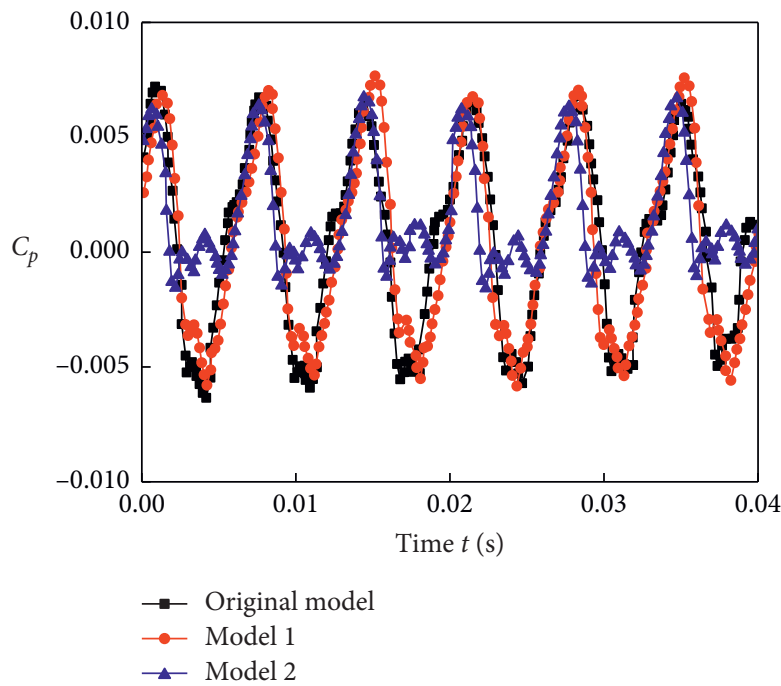

(g)

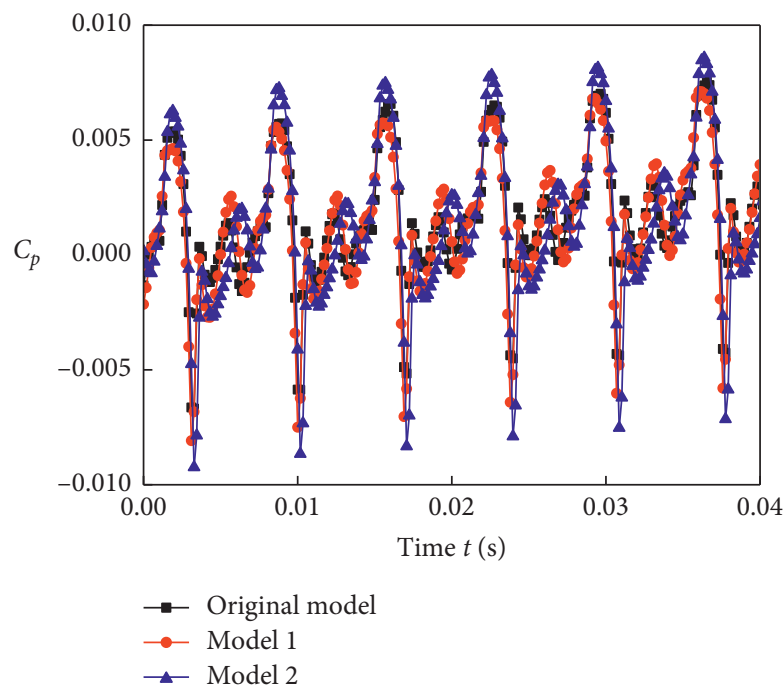

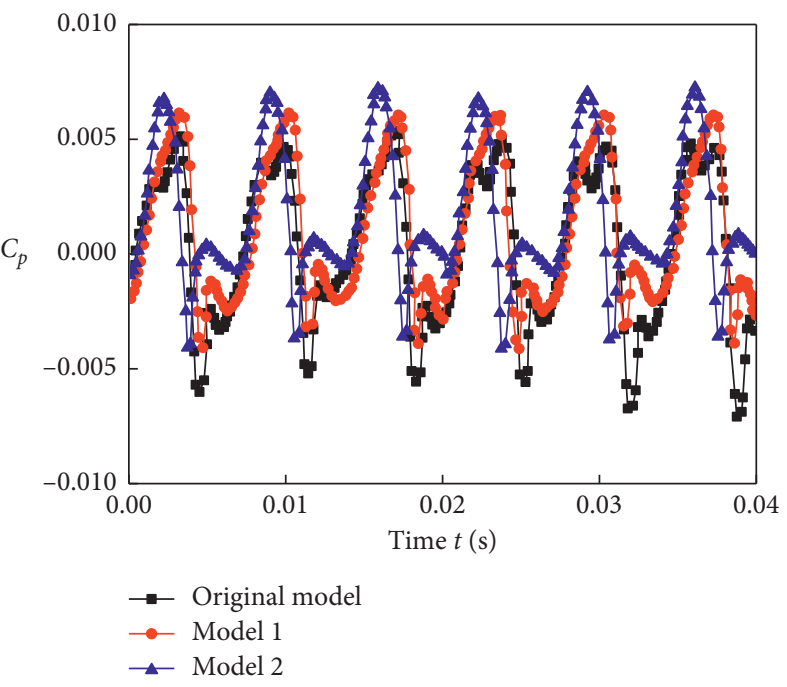

(f)

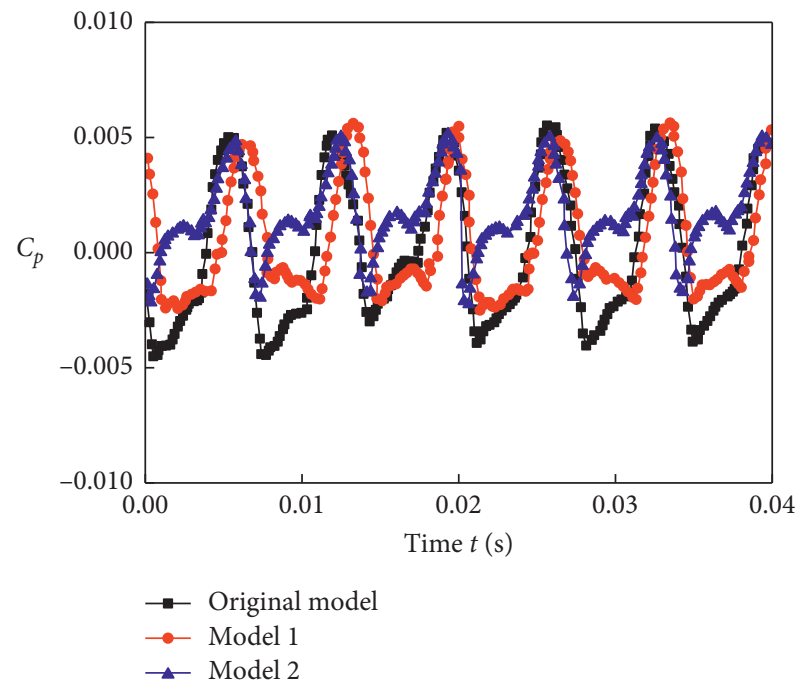

(h)

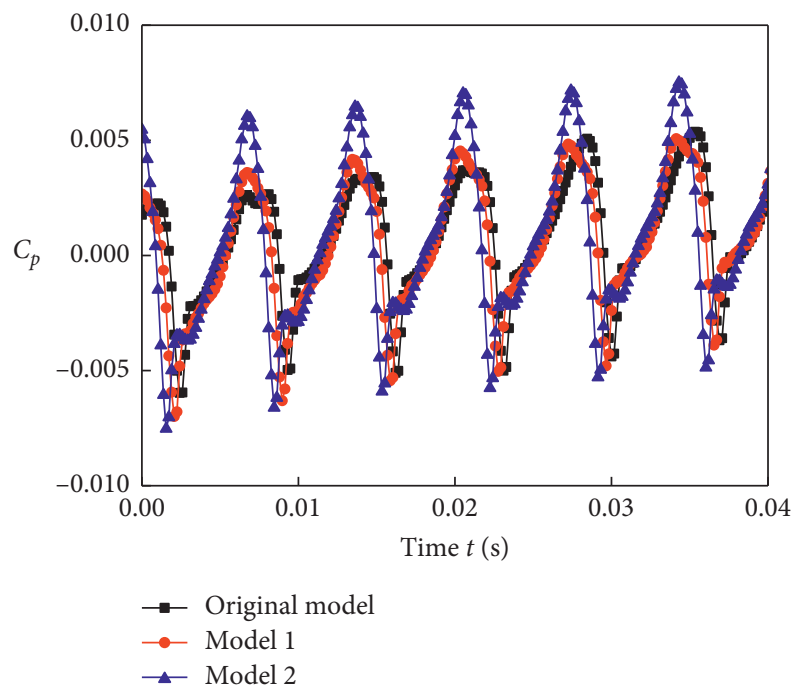

(j)

Figure 10: Continued. 


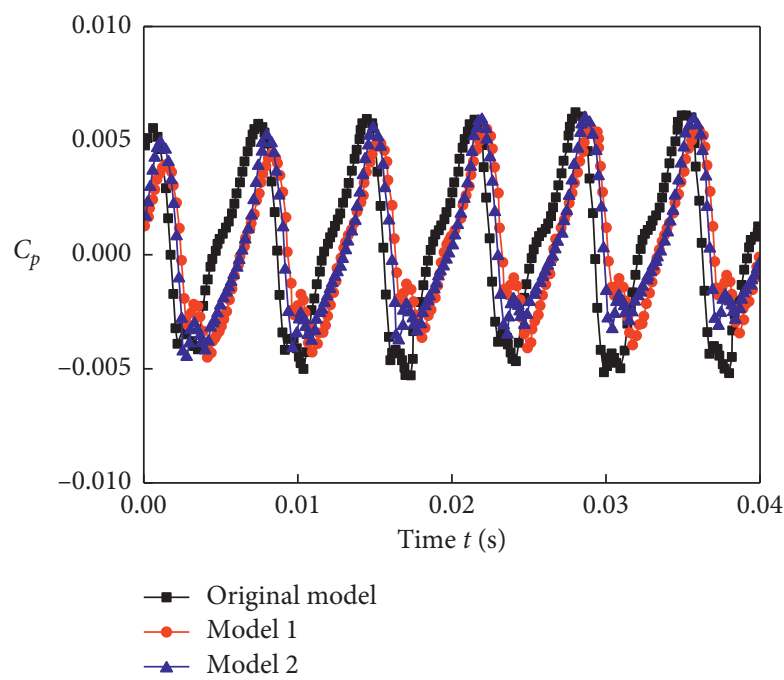

(k)

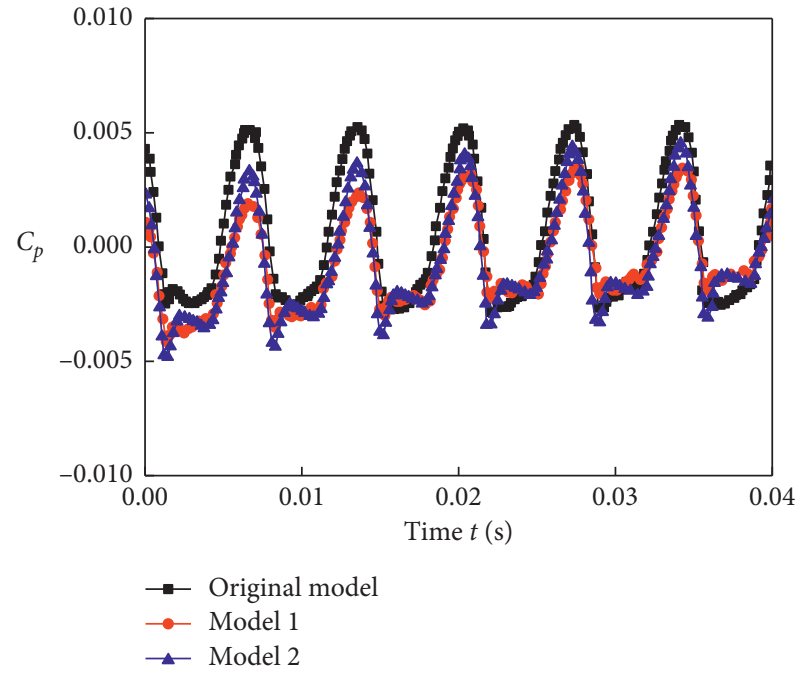

(1)

Figure 10: Time distribution of pressure pulsation in volute. (a) W1, at $0.6 Q_{d}$. (b) W3, at $0.6 Q_{d}$. (c) W4, at $0.6 Q_{d}$. (d) W5, at $0.6 Q_{d}$. (e) W1, at $1.0 Q_{d}$. (f) W3, at $1.0 Q_{d}$. (g) W4, at $1.0 Q_{d}$. (h) W5, at $1.0 Q_{d}$. (i) W1, at $1.4 Q_{d}$. (j) W3, at $1.4 Q_{d}$ (k) W4, at $1.4 Q_{d}$. (l) W5, at $1.4 Q_{d}$.

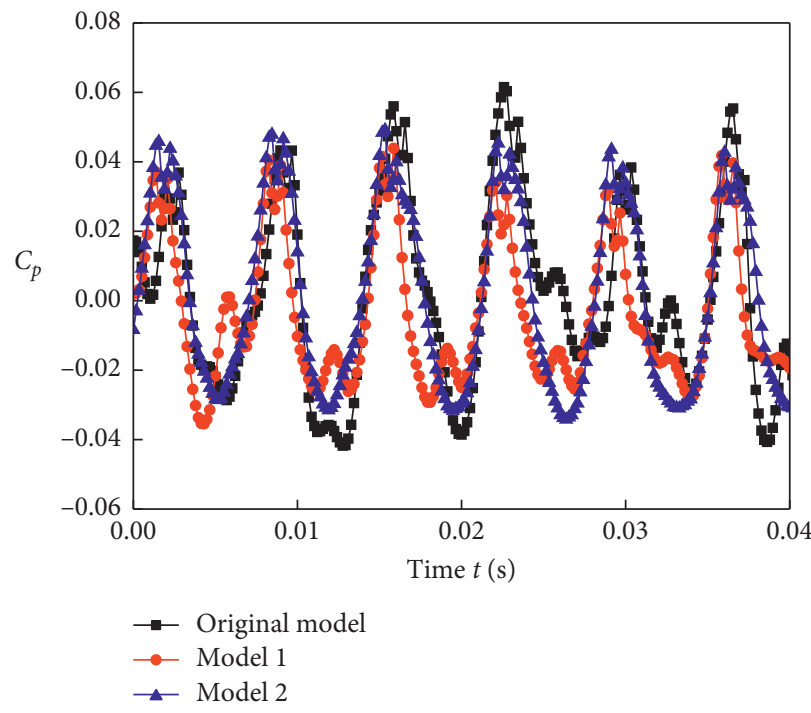

(a)

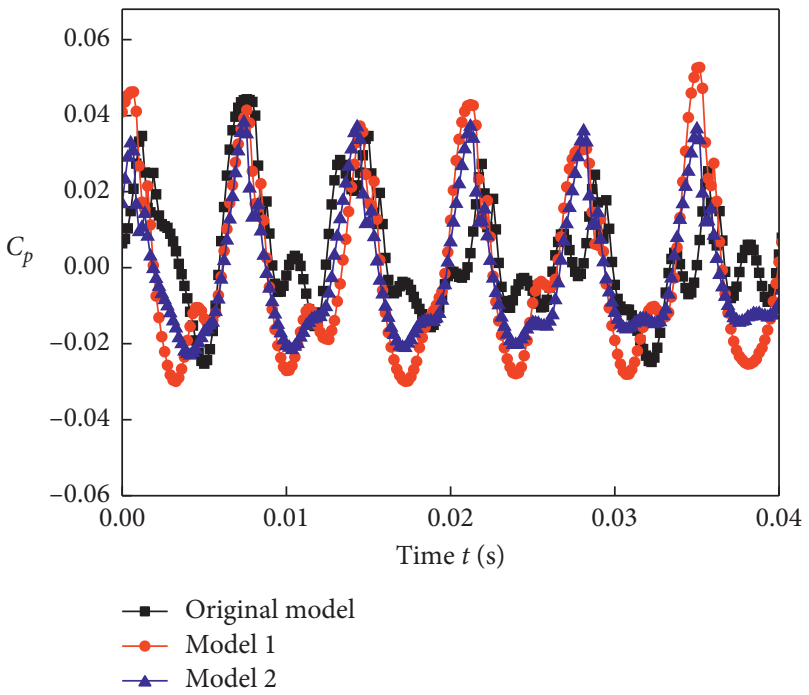

(b)

Figure 11: Continued. 


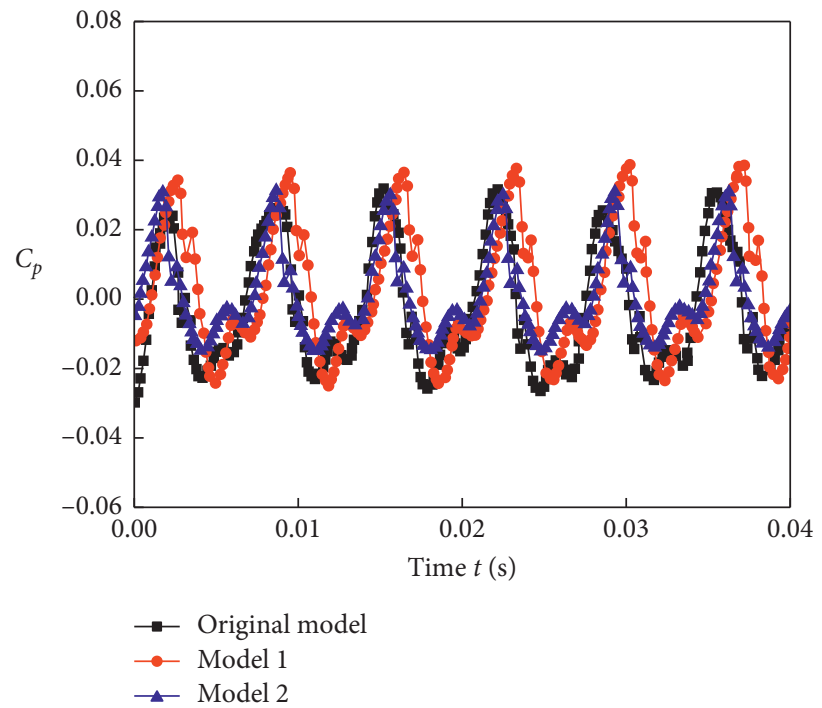

(c)

FIGURE 11: Time distribution of pressure pulsation at the volute tongue under different flow conditions. (a) $0.6 Q_{d}$. (b) $1.0 Q_{d}$. (c) $1.4 Q_{d}$.

waveform distortion at trough vanishes. At $1.4 Q_{d}$, the pulse amplitude of model 1 is higher than that of the original, and the amplitude of pressure fluctuation in model 2 falls dramatically compared with the original model. In summary, when the slot diameter is $180 \mathrm{~mm}$ with a small width, the pressure pulsation amplitude at the tongue increases in a certain extent, but the local waveform distortion weakens. At $1.4 Q_{d}$, the pulsation amplitude decreases significantly when the gap width is large.

\section{Conclusions}

In this paper, the methods of numerical calculation and experiment have been applied to the research on the difference of pump performance, internal flow field, and pressure pulsation characteristic of three pump models, which included the original model, model 1 with $1.5 \mathrm{~mm}$, and model 2 with $6.0 \mathrm{~mm}$ slot width at the diameter of $180 \mathrm{~mm}$. The influence of slot width on the steady and unsteady characteristics of low-specific-speed centrifugal is analyzed, and the main conclusions are as follows:

(1) Numerical calculations of the initial model head and efficiency agree well with the experimental results. The maximum errors of head and efficiency between numerical and experimental are at $1.4 Q_{d}$, and the errors are $4.7 \%$ and $3.1 \%$, respectively.

(2) The gap drainage impeller has a great influence on the head of low-specific-speed centrifugal pumps, and the slot would cause a certain degree of head reduction. The head reduction goes up with the increase of the slot width; meanwhile, higher efficiency can be achieved with smaller slot width. Compared to the original model, the maximum efficiency improvement rate is $3.9 \%$, and the head drop is about $5 \mathrm{~m}$ under each working condition. Reasonable slot scheme can improve the pump performance.
(3) Gap drainage reduces the blockage of impeller outlet outflow, changing the direction of mainstream flow at the gap and strengthening the mainstream suppression on flow separation; however, too small gap width would produce a serious crowding effect, leading to increased flow separation. In addition, the pressure drop at the gap is the main reason for the decrease of pump head, and the excessive gap width will enhance the pressure drop at the gap.

(4) The pressure pulsation under large flow rate can be substantially weakened by the gap drainage; furthermore, the disturbance in impeller outlet can enhance the pressure pulsation at impeller outlet and upstream of volute flow channel, but the disturbance significantly weakens the propagation of pressure pulsation in volute flow channel. Pressure fluctuation intensity in downstream of volute channel decreases greatly and dramatically at $6.0 \mathrm{~mm}$ slot width. Reasonable slot scheme can weaken the development of pressure pulsation of low-specific-speed centrifugal pump, improve its unsteady characteristics, and enhance the operational stability of the pump.

\section{Data Availability}

The data used to support the findings of this study are included within the article.

\section{Conflicts of Interest}

The authors declare that they have no conflicts of interest.

\section{Acknowledgments}

This work was supported by the National Key Research and Development Project (Grant no. 2017YFC0806300), 
National Natural Science Foundation of China (Grant nos. 52079058 and 51979138), Nature Science Foundation for Excellent Young Scholars of Jiangsu Province (Grant no. BK20190101), China Postdoctoral Science Foundation (Grant no. 2020M681520), and Jiangsu Planned Projects for Postdoctoral Research Funds (Grant no. 2020Z031).

\section{References}

[1] Y.-D. Choi, J. Kurokawa, and J. Matsui, "Performance and internal flow characteristics of a very low specific speed centrifugal pump," Journal of Fluids Engineering, vol. 128, no. 2, pp. 341-349, 2006.

[2] B. L. Cui, Z. C. Zhu, J. C. Zhang, and Y. Chen, "The flow simulation and experimental study of low-specific-speed high-speed complex centrifugal impellers," Chinese Journal of Chemical Engineering, vol. 14, no. 4, pp. 435-441, 2007.

[3] Y. Li, X. Dai, and Z. Wang, "Sensitivity of different sealing structures to axial movement of centrifugal pump impeller," Journal of Drainage and Irrigation Machinery Engineering, vol. 39, no. 2, pp. 122-127, 2021.

[4] W. Wang and Y. Wang, "Analysis of inner flow in low specific speed centrifugal pump based on LES," Journal of Mechanical Science and Technology, vol. 27, no. 6, pp. 1619-1626, 2013.

[5] N. Zhang, B. Gao, Z. Li, D. Ni, and Q. Jiang, "Unsteady flow structure and its evolution in a low specific speed centrifugal pump measured by PIV," Experimental Thermal and Fluid Science, vol. 97, pp. 133-144, 2018.

[6] G. Peng, X. Huang, L. Zhou, G. Zhou, and H. Zhou, "Solidliquid two-phase flow and wear analysis in a large-scale centrifugal slurry pump," Engineering Failure Analysis, vol. 114, Article ID 104602, 2020.

[7] W. Shi, L. Li, R. Xu et al., "Effect of blade slotting on radial thrust of single vane centrifugal pump," Journal of Drainage and Irrigation Machinery Engineering, vol. 38, no. 9, pp. $865-870,2020$.

[8] B. Jafarzadeh, A. Hajari, M. M. Alishahi, and M. H. Akbari, "The flow simulation of a low-specific-speed high-speed centrifugal pump," Applied Mathematical Modelling, vol. 35, no. 1, pp. 242-249, 2011.

[9] Y. Yang, L. Zhou, W. Shi, Z. He, Y. Han, and Y. Xiao, "Interstage difference of pressure pulsation in a three-stage electrical submersible pump," Journal of Petroleum Science and Engineering, vol. 196, Article ID 107653, 2020.

[10] L. Bai, L. Zhou, X. Jiang, Q. Pang, and D. Ye, "Vibration in a multistage centrifugal pump under varied conditions," Shock and Vibration, vol. 2019, Article ID 2057031, 9 pages, 2019.

[11] Y. Yang, L. Zhou, J. Hang, D. Du, W. Shi, and Z. He, "Energy characteristics and optimal design of diffuser meridian in an electrical submersible pump." Renewable Energy, vol. 167, pp. 718-727, 2020.

[12] S. Tang, S. Yuan, and Y. Zhu, "Convolutional neural network in intelligent fault diagnosis toward rotatory machinery," IEEE Access, vol. 8, no. 1, pp. 86510-86519, 2020.

[13] D. T. Huang and X. D. Bian, "Application of slotted technique on splitter blade in centrifugal fan," Tsinghua University (Science Technology), vol. 39, pp. 6-9, 1999.

[14] E. Dennis, M. Culley, and M. Brighi, Active Flow Separation Control of a Stator Vane Using Surface Injection in a Multistage Compressor Experiment, ASME Paper, New York, NY, USA, 2003.

[15] Q. Du, J. Zhu, M. Zhou, and W. Li, "Computational investigation of blade slotting on a high-load low-pressure turbine profile at various Reynolds numbers: part I-slotting scheme's verification," Journal of Thermal Science, vol. 20, no. 1, pp. 13-20, 2011.

[16] A. Alaimo, A. Esposito, A. Milazzo, C. Orlando, and F. Trentacosti, "Slotted blades savonius wind turbine analysis by CFD," Energies, vol. 6, no. 12, pp. 6335-6351, 2013.

[17] Z. Liu, K. Yang, W. Lu et al., "Influence of balance hole diameter on flow state at the inlet of centrifugal pump impeller," Journal of Drainage and Irrigation Machinery Engineering, vol. 38, no. 10, pp. 973-978, 2020.

[18] M. Liu, L. Tan, and S. L. Cao, "Influence of geometry of inlet guide vanes on pressure fluctuations of a centrifugal pump," Journal of Fluids Engineering, vol. 140, no. 9, Article ID 091204, 2018.

[19] W. Xiao and L. Tan, "Design method of controllable velocity moment and optimization of pressure fluctuation suppression for a multiphase pump," Ocean Engineering, vol. 220, Article ID 108402, 2021.

[20] Y. D. Han and L. Tan, "Dynamic mode decomposition and reconstruction of tip leakage vortex in a mixed flow pump as turbine at pump mode," Renewable Energy, vol. 155, pp. 0960-1481, 2020.

[21] S. Q. Yuan, J. F. Zhang, J. P. Yuan et al., "Effects of splitter blades on the law of inner flow within centrifugal pump impeller," Chinese Journal of Mechanical Engineering, vol. 20, no. 5, pp. 59-63, 2007.

[22] G. Kergourlay, M. Younsi, F. Bakir, and R. Rey, "Influence of splitter blades on the flow field of a centrifugal pump: testanalysis comparison," International Journal of Rotating $\mathrm{Ma}$ chinery, vol. 2007, Article ID 0, 13 pages, 2007.

[23] D. Georgiev and S. D. Vlaev, "Fluid flow properties of slotted flat- and hollow-blade impellers," Chemical and Biochemical Engineering Quarterly, vol. 22, no. 3, pp. 267-272, 2008.

[24] S. B. Li, P. R. Wei, and H. X. Chen, "Effects of low specific speed centrifugal pumps performance with gap drainage blades," Journal of Shanghai University (Social Sciences Edition), vol. 18, no. 4, pp. 396-400, 2012.

[25] B. Zhu and H.-X. Chen, "Cavitating suppression of low specific speed centrifugal pump with gap drainage blades," Journal of Hydrodynamics, vol. 24, no. 5, pp. 729-736, 2012.

[26] R.-H. Zhang, L.-C. Yun, and J. Li, "The effect of impeller slot jet on centrifugal pump performance," Journal of Hydrodynamics, vol. 31, no. 4, pp. 733-739, 2019.

[27] H. Yan, X. Su, H. Zhang et al., "Design approach and hydrodynamic characteristics of a novel bionic airfoil," Ocean Engineering, vol. 216, Article ID 108076, 2020.

[28] Y. Zhang, W. Zang, J. Zheng et al., "The influence of waves propagating with the current on the wake of a tidal stream turbine," Applied Energy, vol. 290, Article ID 116729, 2021. 